\title{
O ENSINO DE CONCEITOS NA UNIVERSIDADE: O FACEBOOK COMO INSTRUMENTO DE MEDIAÇÃO DIDÁTICA COLABORATIVA
}

\author{
LA ENSEÑANZA DE CONCEPTOS EN LA UNIVERSIDAD: FACEBOOK \\ COMO INSTRUMENTO (APARATO) DE MEDIACIÓN DIDÁCTICA COLABORATIVA
}

\author{
THE TEACHING OF CONCEPTS IN THE UNIVERSITY: FACEBOOK AS A \\ COLLABORATIVE INSTRUMENT OF TEACHING MEDIATION
}

\author{
Dirce Aparecida Foletto de MORAES ${ }^{1}$ \\ Diene Eire de MELLO ${ }^{2}$
}

RESUMO: O presente estudo busca analisar as possibilidades de utilização da rede social Facebook como instrumento de mediação didática colaborativa no ensino de conceitos. A experiência investigada é resultado de uma intervenção didática baseada na mediação como eixo do processo formativo com estudantes universitários de um curso de licenciatura de uma universidade pública. A abordagem qualitativa, na modalidade exploratório-explicativa, norteou a investigação. A teoria da cognição distribuída e suas categorias de: mediação, interação, participação colaborativa e parceria intelectual foram tomadas como base para análise dos dados. Os resultados evidenciam que o Facebook tem um grande potencial como instrumento de mediação a partir das interações evidenciadas por meio do diálogo, do confronto cognitivo e da construção conjunta de significados e também a partir da participação colaborativa que expressou as contribuições dos estudantes para alcançar as metas coletivas por meio da parceria intelectual em busca da compreensão conceitual.

PALAVRAS-CHAVE: Ensino de conceitos. Cognição distribuída. Mediação. Facebook.

RESUMEN: El presente estudio busca analizar las posibilidades de usos de la red social Facebook como un instrumento de mediación didáctica colaborativa en la enseñanza de conceptos. La experiencia investigada es resultado de una intervención didáctica que se basa en la mediación como eje del procedimiento formativo con estudiantes universitarios de un curso de licenciatura en magisterio de una universidad pública. El enfoque cualitativo, en la modalidad exploratorio-explicativa, orientó la investigación. La teoría de la cognición distribuida y sus categorías de: mediación, interacción, participación colaborativa y cooperación intelectual fueron utilizadas para basar el análisis de datos. Los resultados revelan que Facebook tiene un gran potencial como instrumento de mediación a partir de las interacciones evidenciadas por medio del diálogo, del enfrentamiento cognitivo y de la construcción conjunta de significados, también a partir de la participación colaborativa que manifestó las contribuciones de los estudiantes para alcanzar los objetivos colectivos por medio de la cooperación intelectual en busca de la comprensión conceptual.

${ }^{1}$ Instituição: Universidade Estadual de Londrina (UEL), Londrina - PR - Brasil. Docente do departamento de Educação. ORCID: https://orcid.org/0000-0002-1392-1605. E-mail: dircemoraes@uel.br

${ }^{2}$ Instituição: Universidade Estadual de Londrina (UEL), Londrina - PR - Brasil. Docente do programa de pósgraduação em Educação. ORCID: http://orcid.org/0000-0001-6048-8130. E-mail: diene.eire.mello@gmail.com 
PALABRAS CLAVE: Enseñanza de conceptos. Cognición distribuida. Mediación. Facebook.

ABSTRACT: This study aims to analyze the possibilities of using the social network Facebook as an instrument of collaborative didactic mediation in teaching concepts. The investigated experience is the result of a didactic intervention based on mediation as the partnership of the formative process with university students of a licentiate course of a public university. The qualitative approach, in the exploratory-explanatory modality, guided the investigation. The theory of distributed cognition and its categories of mediation, interaction, collaborative participation and intellectual partnership were taken as basis for data analysis. The results show that Facebook has great potential as an instrument of intercession from the interactions evidenced through dialogue, cognitive confrontation and the cooperative construction of meanings from the collaborative participation that expressed the contributions of the students to reach the goals through intellectual partnership in search of conceptual understanding.

KEYWORDS: Concept teaching. Distributed cognition. Mediation. Facebook.

\section{Introdução}

As atividades e o meio sociocultural têm papel fundamental na aprendizagem e no desenvolvimento cognitivo dos sujeitos e por isso, ao pensar nos aspectos que envolvem a formação conceitual do estudante universitário contemporâneo, enfatiza-se a necessidade de um ambiente interativo, no sentido de que ao compartilhar conhecimento, ocorre a apropriação de aspectos culturais e o desenvolvimento de conceitos. No entanto, o tipo de atividade cognitiva varia de acordo com a natureza das atividades desenvolvidas, as mudanças e os fatores históricos de um determinado contexto e, principalmente, a qualidade do elemento mediador. Em virtude disso, se faz necessário considerar os ambientes e os artefatos com os quais os sujeitos atuam, interagem, como estes influenciam em seu desenvolvimento e podem mediar as atividades cognitivas.

Salomon, Perkins e Globerson (1991) apontam que a mediação que ocorre em situações de interação entre o sujeito e os artefatos de um contexto pode favorecer a criação de zonas de desenvolvimento proximal, isso porque o segundo atua como elemento mediador na resolução de problemas ou realização das tarefas do primeiro. Os autores evidenciam que o artefato deixa um resíduo cognitivo ao exigir novas habilidade e estratégias mentais que ajudam o sujeito a melhorar seu desempenho. Porém, esse não é um processo natural que ocorre pelo simples uso dos artefatos, mas requer práticas baseadas na parceria e na colaboração, além de novas funções, habilidades e o engajamento em atividades. 
Como mediadores das atividades humanas, os artefatos exercem um papel importante no que se refere à distribuição da cognição, e isso se amplia com o surgimento dos digitais, pois são considerados "ferramentas inteligentes" (PEA, 1993) capazes de aumentar as habilidades cognitivas e oportunizar diferentes experiências.

Como instrumentos culturais mediadores das interações e das atividades humanas, as tecnologias digitais, possivelmente, contribuem para mudanças em algumas práticas sociais como a comunicação, a socialização, a organização, a mobilização e a aprendizagem (COSTA; DUQUEVIZ; PEDROZA, 2015). Neste sentido, o docente, ao desenvolver ações intencionais, pode selecionar ferramentas adequadas e levar o aluno a participar de experiências de aprendizagem mediadas, direcionando a construção do conhecimento do estudante.

No entanto, o que vai fazer a diferença não é o artefato em si, mas a natureza da atividade proposta e o que esta é capaz de desenvolver ou proporcionar de maneira diferente do vivido pelo estudante em sala de aula. Nesta perspectiva, este estudo buscou analisar as possibilidades de utilização do Facebook como instrumento de mediação didática colaborativa no ensino de conceitos na universidade.

\section{As ferramentas digitais como instrumento de mediação no ensino e na aprendizagem de conceitos}

O sujeito adulto que está na universidade, diferentemente da criança, vive de forma complexa, aprende e se desenvolve interagindo em múltiplos ambientes, mediado por diferentes situações (SMITH; POURCHOT, 1998). Dessa forma, “[...] a natureza da aprendizagem dos adultos é tanto estimulada como estruturada pela experiência de vida adulta" (LEMME, 1995, p. 148), as quais vão sendo internalizadas e tornam-se uma ponte para o desenvolvimento cognitivo.

Com isso, sua aprendizagem torna-se um processo interno, dinâmico e socialmente mediado pelos aspectos sociais, psicológicos, profissionais, educacionais e pelos enfrentamentos da vida cotidiana. $\mathrm{O}$ adulto não só aprende como também ensina nas mais diversas situações que vivencia, nas relações sociais com seus pares, com os familiares, na chegada à universidade, nos problemas do dia-a-dia, nas mudanças e exigências no trabalho, nas implicações sociais e emocionais e ainda nas questões da própria sociedade. $\mathrm{O}$ trabalho com adultos implica em aprendizagem cooperativa, colocando-os frente às situaçõesproblema, a fim de que possam caminhar para a autoformação profissional e a construção de 
conceitos de forma criativa e não mecânica e direcionar seus processos mentais. O saber se constrói socialmente por meio da interação dos alunos envolvidos no processo, sob a mediação pedagógica do professor.

Tal afirmação se consolida no entendimento de que a aprendizagem se dá pela mediação que ocorre na relação de confrontos, nos quais primeiramente "[...] outras pessoas atuam sobre ele; se produz então a interação com seu entorno e, finalmente, é ele próprio quem atua sobre os demais e tão somente ao final começa a atuar em relação consigo mesmo [...]" (VIGOTSKI, 1995, p. 232), constituindo-se como um processo social e cultural.

Portanto, ao pensar no processo de formação conceitual do sujeito adulto, se faz necessário considerar que o funcionamento dos processos cognitivos se refere ao ambiente sociocultural, às experiências que vivencia e os ambientes em que atua, interage e aprende, além da maneira como os ambientes e as ferramentas agem no processo formativo do sujeito.

$\mathrm{Na}$ atualidade, as diferentes interfaces e ferramentas digitais de compartilhamento disponíveis favorecem o trabalho coletivo e contribuem para uma aprendizagem mais interativa, colaborativa e autônoma, além de possibilitar a troca de experiências e a distribuição da cognição (SALOMON, 1993). De acordo com Costa, Duqueviz e Pedroza (2015, p. 605), diante do cenário social da atualidade, em que os jovens são os maiores usuários dos artefatos digitais, é de se esperar que estes "[...] contribuam ou provoquem mudanças na forma de socializar e interagir com outras pessoas, bem como no modo de colaborar e compartilhar informações, influenciando nos processos de aprendizagem". Assim, a ideia de uma aprendizagem linear e isolada não se sustenta mais em uma sociedade mediada pelos artefatos digitais, visto que a colaboração e a interação são conceitos presentes nas práticas culturais realizadas entre os jovens contemporâneos.

Para Ito $(2009$, p. 01), o grau elevado de conhecimento “[...] técnico e pensamento sistêmico, exigidos nas práticas digitais contemporâneas, bem como as oportunidades para a aprendizagem baseada em pares e a colaboração em redes on-line, criam oportunidades para a aprendizagem científica" e trazem resultados diversificados que podem ser um fator positivo quando pensamos nos processos formativos desses sujeitos.

Em uma pesquisa na base de dados do SciELO - Scientific Electronic Library Online, considerando o período de 2014 a 2018, com os descritores: tecnologias digitais, ensino, aprendizagem, mediação, bem como os critérios de inclusão e exclusão, foram encontrados cinco artigos que apontam na direção dos artefatos digitais como mediadores das práticas educativas. Scorsolini-Comin (2014) constata, em sua pesquisa, que os dispositivos digitais possibilitaram a ampliação e flexibilização dos espaços de aprendizagem. O estudo realizado 
por Fernandes e Martins (2015) apresenta uma experiência com a robótica como mediadora da produção escrita com crianças do primeiro ciclo. Os autores consideram que tal experiência abriu portas para a criação de repertórios de saberes e significados.

Costa, Duqueviz e Pedroza (2015) também realizaram uma pesquisa com o propósito de discutir o uso das TDIC como instrumentos mediadores da aprendizagem dos nativos digitais, considerando que as mudanças nas formas de interações sociais da atualidade contribuem na constituição da subjetividade dos jovens. Como conclusão, os autores reconhecem a função dos instrumentos mediadores do processo de aprendizagem dos nativos digitais. O estudo realizado por Tezani $(2017,305)$ conclui que os dispositivos digitais “[...] têm exercido a função de instrumentos mediadores ao processo de ensinar e aprender dos nativos digitais, mesmo que de forma ainda insipiente em alguns contextos". O estudo realizado por Sengik, Valentini, Timm (2017) concluiu que um software foi mediador do desenvolvimento das habilidades de leitura de crianças.

Estes e outros estudos evidenciam um novo cenário que se apresenta a partir de uma cultura digital, colocando "em cheque" a estrutura e as práticas das instituições educativas que priorizam a aprendizagem individual. Contrariando tal o entendimento, Coll, Mauri e Onrubia (2010) defendem uma mudança na perspectiva educativa: de um processo de ensino e aprendizagem individual para uma concepção deste como processo social, interativo e mediado, no qual o resultado da aprendizagem advém do trabalho conjunto e da interação entre professor, estudantes e conteúdos e os artefatos que fazem parte do contexto.

A teoria da cognição distribuída defende que o processo mental está relacionado ao contexto sócio-histórico e por isso considera que a aprendizagem é uma construção social que ocorre com a mediação na relação ente os sujeitos e destes com os artefatos. Esta abordagem teórica entende que a distribuição da cognição, ou seja, que o processo cognitivo não se dá unicamente entre artefatos e sujeitos, mas nas diversas situações da cultura, em um processo colaborativo e compartilhado.

Como exemplo, Salomon (1993) destaca atividades em que as pessoas, os artefatos, os ambientes e as tarefas executadas se tornam parceiros cognitivos ao mediar os sujeitos em suas atividades. Para o autor, em uma situação em que os jovens estudantes realizam práticas de escrita com o apoio de uma ferramenta computacional de forma coletiva e colaborativa, a parceria com o artefato não apenas auxilia na realização da tarefa cognitiva de forma mais simples, mas favorece a melhoria da capacidade de escrita dos estudantes a partir das orientações providas pela ferramenta e pela parceria entre os pares. Com isso, a ferramenta 
exerce um papel mediador e deixa certos "resíduos cognitivos", que ajudam o estudante a se desenvolver.

A mediação provoca transformações, almeja o desenvolvimento dos sujeitos e tem um papel crucial no processo de distribuição da cognição, no entanto, depende do trabalho com diferentes tipos de atividades e variadas estratégias (COLE; ENGESTRÕM,1993). No entanto, é importante ressaltar que o processo de mediação não inclui somente atividades com objetos físicos, como ferramentas e instrumentos, ou simbólicos, como gráficos, textos, imagens, mas também está presente nas relações sociais, nas ações e no próprio ambiente (PEA, 1993). Assim, todas as outras ações, como a interação, a colaboração, a parceria, a negociação e o próprio contexto são recursos mediadores das atividades cognitivas, a partir das relações que se estabelecem.

Werstch e Tulviste (2013) destacam que a mediação não facilita a aprendizagem, mas seu efeito está em torná-la qualitativamente diferente, dependendo da maneira como os sujeitos vão utilizá-la para conduzir sua ação.

Sobre os artefatos como mediadores, Pea (1993) aponta que vivemos em um ambiente constituído por eles e que seu uso constante os torna mediadores das ações humanas, formando uma estrutura da atividade. Para Cole e Engestrõm (1993), ao mediarem as atividades dos seres humanos, os artefatos implicam as formas como ocorre a distribuição da cognição dos sujeitos, constituindo-se como característica fundamental dos processos psicológicos superiores.

Assim, no contexto atual, os ambientes virtuais de compartilhamento, muito utilizados pelos jovens, tornam-se ferramentas propícias a serem utilizadas na universidade como elementos mediadores na formação conceitual, pois fornecem aos estudantes e professores suporte para participar de comunidades, realizar atividades coletivas, ajudarem-se mutuamente, expandirem as práticas pedagógicas e os processos formativos, além de tornarem-se instrumentos didáticos mediadores na formação conceitual. Por serem ferramentas mediadoras, “[...] refletem uma grande noção, que é a propagação e distribuição de conhecimento comum nas interações sociais. Essa noção está implícita na teoria da cognição distribuída, em que o grupo toma a forma de conhecimento compartilhado" (MANSOUR, 2009, p. 249).

\section{Procedimentos metodológicos}


Este estudo é parte integrante do projeto de pesquisa intitulado "Tecnologias, Didática e Aprendizagem", desenvolvido na Universidade Estadual de Londrina, o qual focaliza e investiga boas práticas educativas com as tecnologias digitais. Nesta direção, analisa as possibilidades de utilização da rede social Facebook como instrumento de mediação didática colaborativa na formação de conceitos em uma disciplina do curso de Pedagogia.

A abordagem qualitativa, na modalidade exploratório-explicativa, norteou a investigação, juntamente com os seguintes procedimentos para coletar os dados: observação participante, questionário e análise documental das narrativas e do material encontrado no grupo do Facebook. A teoria da cognição distribuída defendida por Salomon, Cole e Engestrõm, Pea e Brown et al. (1993), Karasavvidis (2002) e suas categorias de mediação: interação, participação colaborativa e parceria foram tomadas como base teórica para análise dos dados. Esta teoria entende que as capacidades mentais operam de forma distribuída a partir da mediação das ações coletivas que ocorrem nas diversas situações e experiências e nas formas de uso dos artefatos em suas atividades.

A teoria explica que a mediação, por meio da interação, envolve o compartilhamento de experiências e conhecimentos e contribuições dos membros do grupo afetando-se reciprocamente. As práticas de interação podem ocorrer na relação entre sujeitos e destes com os artefatos (SALOMON, 1993). A mediação por meio da parceria intelectual se dá nos momentos em que ocorre uma postura de cooperação, no sentido de o sujeito responsabilizarse por si e pelo outro, auxiliando-o em sua aprendizagem. Já a mediação por meio da participação colaborativa se refere às contribuições que os sujeitos manifestam durante o trabalho para alcançar as metas comuns, que podem servir como apoio para avançar a compreensões conceituais mais complexas (MORAES, 2017).

O público-alvo foi constituído por um grupo de 41 estudantes do primeiro ano do curso de Pedagogia de uma universidade pública do interior do Paraná. O lócus da pesquisa foi uma intervenção didática realizada durante um semestre para ensinar conceitos na disciplina de Educação e Tecnologia. Entretanto, apesar do uso de outros aplicativos e artefatos terem sido utilizados, o presente estudo focalizou somente o uso da rede social Facebook, proposto pela docente, como espaço para a realização de algumas atividades visando o ensino dos conceitos de tecnologia e cibercultura.

As análises foram elaboradas considerando todo o conjunto de dados coletados, buscando evidenciar os resultados e as respostas para o objetivo aqui proposto. Após a análise dos dados, procede-se à triangulação dos dados, pois esta é uma das formas de assegurar a 
validade da pesquisa ao combinar e colidir variadas fontes e instrumentos, considerando os significados do contexto histórico e cultural em que a pesquisa ocorre. Essa fase tem por objetivo "[...] abranger a máxima amplitude na descrição, explicação e compreensão do foco em estudo" (TRIVIÑOS, 1990, p.138).

\section{O facebook como instrumento de mediação didática colaborativa no ensino de conceitos}

A intervenção didática analisada teve, dentre suas atividades, a proposta de formação de um grupo fechado na rede social Facebook. De acordo com Mattar (2013), professores e alunos se aproximam, pois a troca de informações pessoais possibilita a comunicação e a interação teórica, aumentando a credibilidade do professor.

A primeira atividade solicitada pelo docente consistiu na expressão pessoal do significado do conceito de tecnologia na vida cotidiana. As respostas deveriam ser expressas por meio de uma foto da realidade e uma poesia produzida pelo estudante. O objetivo desta atividade era investigar o conhecimento prévio dos jovens e, posteriormente, desconstruí-los.

Nessa atividade, dos 41 participantes, 36 realizaram a atividade. As fotos de artefatos que os estudantes consideravam tecnologias de informação e comunicação, como celular, computador, TV, fone de ouvido, telefone, lideraram as postagens, totalizando 19 fotos. Os aparelhos elétricos, como ventilador, geladeira, forno de micro-ondas, máquina fotográfica, de lavar, de cortar tecidos e caixa eletrônico formaram o segundo grupo, totalizando 13 postagens. Além desses, identificamos três fotos de carro e uma de relógio.

Em relação às poesias produzidas pelos estudantes, foi possível identificar que as compreensões se voltavam mais para a contemplação, admiração e encantamento pela tecnologia do que para uma compreensão crítica. Das 36 poesias, 30 mostraram que as tecnologias da atualidade "atendem às necessidades", "torna a vida mais fácil" e, além de serem essenciais, são melhores que as anteriores, evidenciando o consumo e a dependência. A seguir, alguns excertos:

\section{Celular meu companheiro \\ Todas as horas presente \\ Obrigada por existir \\ Com você fico contente (Aluna 08).}

Graças a esta invenção tecnológica temos uma vida mais prática e flexível! (Aluna 29).

A relação de encantamento e proximidade com as tecnologias da atualidade era tão intensa entre os jovens que algumas poesias manifestaram agradecimento a certas invenções, 
como demonstram alguns excertos.

Em nome de todos quero agradecer ao criador do ventilador e dizer, obrigado por nos ajudar a não derreter. Um muito obrigado à tecnologia (Aluna 22).

Você chegou de mansinho

Tinha apenas ligações, mensagens e joguinhos

Hoje não consigo viver sem você

Te uso para trabalhar, badalar e brincar

Muito obrigada ao criador do meu celular (Aluna 31).

Somente três estudantes elaboraram poesias que se distanciaram do olhar contemplativo, expressando uma compreensão mais crítica acerca dos significados que os artefatos evocam nas nossas vidas. Estas alunas mostraram uma compreensão sobre o papel da tecnologia na sociedade e de algumas dimensões desse conceito. A seguir, dois excertos:

\author{
Pequena máquina de relações \\ Qual cria pontes invisiveis, \\ Notícias, alegrias e tristezas \\ Conecta-nos ao mundo. \\ Teria Einstein razão? \\ A tecnologia excedeu nossa humanidade? (Aluna 02).
}

A tecnologia não foi criada para o bem,

Evoluiu, com o tempo, pra nossa realidade, aproximando as pessoas que também sentem saudade.

Mas será que também não ficamos refém? (Aluna 36).

$\mathrm{Na}$ sequência, ainda como parte da atividade, os alunos foram convidados a participar de um chat, na mesma rede social, com a seguinte pergunta: Diante das postagens apresentadas pelos colegas, o que você/s pensa/m sobre a presença da tecnologia em sua vida cotidiana?

Nessa proposta verificamos a participação de 22 estudantes, os quais se divergiram em três grupos: o primeiro, com 14 jovens, entendendo a tecnologia como algo essencial e necessário, pois, além dos benefícios que traz, facilita a vida. Um segundo grupo, com 4 jovens, se vê como dependente da tecnologia, e o terceiro grupo, também com 4 estudantes, considera sua importância, mas consegue manifestar um olhar mais crítico em relação ao poder e ao papel da tecnologia, percebendo suas ambivalências.

Com essas atividades foi possível identificar o que e como pensavam os estudantes sobre o conceito inicialmente, ou seja, não só os conhecimentos prévios, mas também as concepções e as crenças que traziam do seu cotidiano. Os dados foram muito relevantes no sentido de direcionar os encaminhamentos posteriores para o trabalho com esse conceito. 
Os estudantes precisam vivenciar situações em que seus conhecimentos espontâneos sejam colocados em "cheque", para que, assim, possam desmistificar ideias ambíguas, ou do senso comum, e avançar rumo aos conhecimentos científicos. Sem isso, corre-se o risco de estudar um assunto, mas não se apropriar dele enquanto conhecimento científico. Herrero e Brown (2010, p. 257) expressam que, “[...] quando as pessoas de uma comunidade educacional participam juntas, contribuindo com seu conhecimento prévio e considerando as questões em suas várias perspectivas, todos aprendem mais”, pois são confrontados e precisam elaborar novos modos de pensar.

Em relação às categorias da teoria da cognição distribuída, nesta atividade não foi possível verificar nenhuma delas, tendo em vista que nesta fase o trabalho foi individual. No entanto, por ser um espaço mais informal, a rede social possibilitou a expressão de ideias de maneira mais livre e espontânea por parte dos estudantes, as quais serviram como elementos para que o docente pudesse conhecer e explorar os conhecimentos iniciais dos jovens.

Outra proposta por parte do docente foi convidar os estudantes a contribuir com o grupo na formação conceitual com postagens e inserções de materiais relacionados ao conceito, sem menção de nota ou de obrigação, mas de forma livre, no sentido de contribuir na compreensão conceitual.

Nesta atividade foi possível perceber que, no início, agiam de forma tímida e pouco participativa, mas aos poucos foram ampliando a contribuição, demonstrando uma participação espontânea e mais efetiva. Durante todo o período em que foi trabalhado o conceito de tecnologia foi possível identificar 21 postagens, das mais diversas formas: vídeos explicativos sobre o conceito, imagens com comentários e reportagens. Assim, o Facebook foi se tornando um espaço de troca e compartilhamento, mas sem evidências de mediação.

Por serem espontâneas e não direcionadas, as postagens permitiram perceber vários comportamentos e formas de pensar sobre o conceito por parte dos estudantes. Algumas postagens evidenciavam mudança de pensamento, ou seja, de admiração e veneração pelas tecnologias para um olhar mais crítico. Em relação à percepção crítica, entendemos que esse é um aspecto muito importante no desenvolvimento do sujeito, inclusive não só como futuro professor, mas como cidadão, como exemplifica o excerto de uma postagem:

Pesquisando sobre tecnologia encontramos esta imagem que nos chamou bastante atenção. Ao pesquisarmos sobre a imagem descobrimos que foi tirada no ano de 2005, e que se trata de uma criança chinesa brincando em meio a toneladas de lixo tecnológico. Século XXI em direção ao mundo Global??! (Grupo de estudantes) 
Por ser uma imagem chocante, provocou a participação de outros estudantes relacionando com as discussões em sala e formando opiniões críticas sobre o assunto, conforme alguns excertos:

Podemos pensar no que foi dito na última aula, sobre as ambivalências da tecnologia. Uma superprodução de aparelhos tecnológicos sem ao menos ter um descarte correto. Toneladas de lixo tecnológicos enviados a países subdesenvolvidos, sendo mascarados por "caridade". Como a coca-cola no texto que o professor postou que quer mascarar o incentivo ao consumo do produto dizendo ao seu usuário: "pode beber a vontade, que não causo mal algum a saúde, comprovado cientificamente” (Aluna 12).

Concordo, essa imagem é muito triste e impactante! O capitalismo nos induz a consumir de maneira desenfreada e nem sempre permite a reflexão sobre o que acontece. Os produtos tem uma vida útil e programada, somos quase obrigados a descartar, mas triste é estar ciente da realidade e não conseguir revertê-la (Aluna 18).

Resultado de um consumismo desenfreado, sem pensar nas consequências, ou seja, a tecnologia evoluiu, mas a consciência, não, isso é ambivalência (Aluna 33).

Nestas postagens evidenciamos a mediação por meio da participação colaborativa. Esta se refere às várias contribuições dos sujeitos com materiais e comentários para alcançar as metas, que podem servir como apoio para avançar a compreensões conceituais mais complexas. Ao contribuírem postando materiais pesquisados e elaborados para auxiliar no entendimento do conceito de tecnologia e suas ambivalências, os estudantes não só cumpriram a tarefa, mas também exerceram uma postura de cooperação para atingir o objetivo comum, auxiliando, assim, os demais colegas em suas aprendizagens. Para Salomon (1993), a mediação por meio da participação colaborativa se refere às contribuições entre os sujeitos em um determinado trabalho, as quais podem favorecer compreensões conceituais mais complexas.

Assim, de forma colaborativa, os estudantes pesquisam, trabalham, aprendem e desenvolvem seus processos cognitivos. Conforme Brown et al. (1993), o trabalho colaborativo assegura ao grupo um desempenho mais elevado e maduro, ainda que nem todos os membros sejam totalmente capazes de participar de modo efetivo.

Sob essa perspectiva, a educação deveria minimizar a ênfase no trabalho individual e o trabalho colaborativo (PEA, 1993), pois, dessa forma, os alunos se tornam mediadores entre si e podem se tornar produtores, em vez de somente receptores de conhecimento.

A postagem foi um elemento chave para a intervenção do professor na formação do conceito, que propôs uma nova atividade a ser realizada naquele espaço. Esta consistiu em 
solicitar aos estudantes exemplos e comentários sobre as ambivalências da tecnologia, confrontando com o texto sugerido para leitura. A atividade, realizada em grupo, totalizou quinze postagens e evidenciou diferentes formas de leitura e compreensão sobre as ambivalências e reflexões relacionadas ao texto.

As postagens se mostraram favoráveis, no sentido de proporcionar esclarecimento entre os próprios alunos em relação aos diferentes aspectos que envolvem a tecnologia e suas ambivalências, entendendo-a de forma crítica, sem venerá-la ou abominá-la. Apresentamos alguns excertos:

É necessário quebrarmos um paradigma em relação à tecnologia. Atualmente tendemos fortemente a pensar que ela é algo desumanizador no sentido de que com ela nos transformamos em máquinas, ou, que as máquinas nos "transformam" semelhantes a elas [...] Segue uma entrevista sobre tecnologias e empregos (Aluna 03).

Refletindo sobre "A tecnologia: Um modo de transformar o mundo carregado de ambivalência", e a letra da música "Do The Evolution" da banda estadunidense Pearl Jam e seu clipe que retrata o processo evolutivo da espécie humana intrinsecamente ligada à criação e desenvolvimento da tecnologia. Leva a crer que os usos e fins que o homem dá a tecnologia é que a torna algo que possa vir contribuir beneficamente para a humanidade ou de forma extremamente nociva [...] (Aluna 10).

Uma das evidências notadas no vídeo que assistimos é que a tecnologia vem se transformando de geração a geração, os conceitos e formas se modernizam gradativamente [...] (Grupo 08).

Ao analisar as postagens, foi possível identificar, em quase sua totalidade, que os estudantes expressaram seus pensamentos associados a algum recurso, seja um vídeo, imagem ou música, como se percebe nos excertos. Tal aspecto aponta evidências de que, para aprender, eles passam a relacionar o conteúdo com diferentes recursos, transformando-os em mediadores cognitivos. Segundo Salomon (1993), não podemos considerar que o sujeito é totalmente responsável por sua atividade intelectual, assim como o artefato por ele utilizado também não. O que vai fazer a diferença, segundo o autor, é a oportunidade de participar do processo de forma interativa, no qual a parceria trará contribuições para sua atividade cognitiva.

A partir deste momento foi possível perceber que os estudantes assumiram o compromisso de trazer contribuições, comentários pertinentes e materiais que de fato acrescentassem na compreensão do conceito, evidenciando um salto maior no compromisso assumido. 
Nestas postagens foi possível identificar novamente evidências da categoria participação colaborativa, mas junto com ela, a parceria intelectual. Percebemos que os estudantes passaram a assumir uma postura de corresponsáveis na construção do conceito e não de somente espectadores, ou "tarefeiros", que devem cumprir o que lhes é solicitado. De acordo com Salomon (1993), a parceria intelectual se dá nos momentos em que ocorre uma postura de cooperação, no sentido de se responsabilizar por si e pelo outro, auxiliando-o em sua aprendizagem.

A partir da mudança de postura dos estudantes, o Facebook passou a servir como ferramenta mediadora do diálogo, oportunizando a manifestação livre de pensamentos, opiniões e conhecimentos científicos sobre o conceito estudado, o qual possivelmente não ocorreria no espaço cotidiano da sala de aula. Entendemos aqui que as práticas vivenciadas com a ferramenta digital ampliaram o pensamento, oportunizou novos olhares, relações entre o conceito e a realidade e provocou questionamentos. De acordo com Brown et al. (1993), os artefatos digitais não devem servir somente como ferramentas de comunicação e colaboração, mas também como mediadores das aprendizagens.

Durante o período em que o conceito de cibercultura foi trabalhado, identificamos uma ampliação do número de postagens, totalizando cinquenta e seis, sendo dezessete imagens, treze vídeos, cinco tirinhas, três reportagens, dois comentários pessoais, duas definições a partir de referencial teórico, uma produção de poesia e uma entrevista. Além destas, outras doze postagens foram postadas sinalizando uma visão mais crítica em relação ao uso dos artefatos digitais na sociedade e não ao conceito de cibercultura, especificamente, conforme proposto.

No começo identificamos que os jovens contribuíam de forma aleatória com postagem de imagem ou vídeo. Aos poucos, alguns estudantes tiveram a iniciativa de escrever comentários convidativos ao diálogo e à reflexão, ou seja, passaram a "produzir" mais conteúdo do que apenas “depositar” um conteúdo pronto, conforme as figuras a seguir:

Figura 1 - Entendimento do conceito de cibercultura elaborado pela aluna 11 
A relação entre a sociedade, a cultura e as tecnologias digitais formam hoje uma nova organização entre as pessoas. Com outros costumes. atitudes e pensamentos. Um novo meio de comunicação vem se desenvolvendo, baseando-se em uma cultura conectada aos

computadores e a tudo que está ligado a eles. Assim, surge a cibercultura que cresce dentro do ciberespaço.

Com mídias completamente diferentes das que existiam há décadas atrás, a cibercultura tem se manifestado de maneira que já somos dependentes de sua tecnologia, seja em casa, no trabalho, na escola e em qualquer outro lugar. O que nos faz refletir se a tecnologia dita quem somos e quem seríamos sem ela.

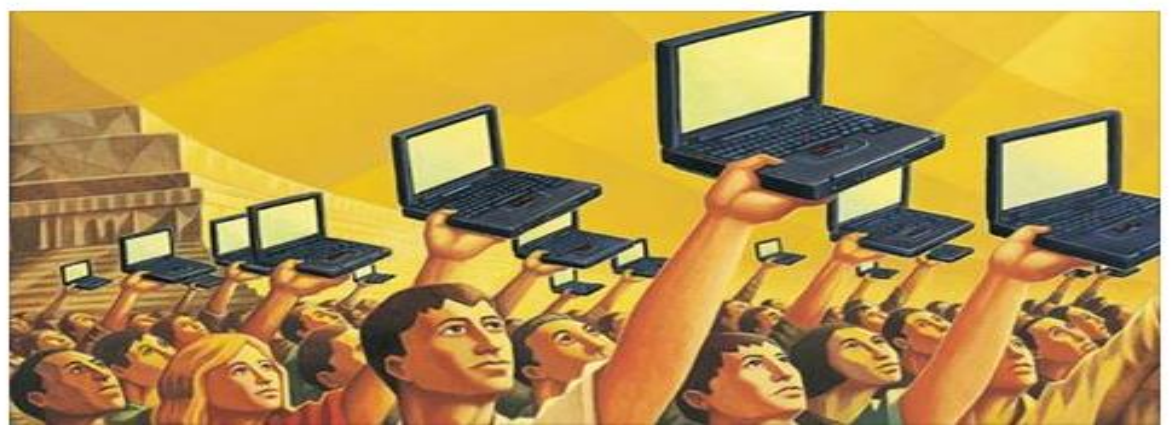

Fonte: Facebook (2018)

Outro exemplo de contribuição para compreensão do conceito foi uma poesia produzida por iniciativa própria de uma aluna sobre o conceito de cibercultura. Consideramos que nessa atividade também é possível identificar a categoria participação colaborativa e a parceria intelectual.

Ah! Cibercultura, sempre provocando debates!

A quem diga que você cria caminhos para a criatividade

Outros se "descabelam" para comprovar que é uma contribuição para a maldade.

Cibercultura, cibercultura

Deixa esse embate "rolar"

Deixa o circo pegar fogo

Heroína ou vilã, não tem jeito, vão te rotular

Ah cibercultura

Não fique triste!

Quem sabe a conclusão um dia há de chegar

E eles percebam que a ambivalência em você está!!

A parceria intelectual instiga o estudante a uma postura de cooperação e compromisso com sua aprendizagem e com as dos demais colegas. Assim, se praticada de forma contínua e harmônica, propicia uma cultura diferenciada no ambiente escolar, pois os estudantes passam a perceber que os objetivos serão atingidos com a participação e o compromisso de todos (MORAES, 2017).

Uma observação importante é a de que, nas primeiras postagens, não havia manifestação dos estudantes, somente curtidas. Aos poucos, essa postura também foi alterada e os estudantes passaram a interagir com os demais colegas. Assim, percebemos que a 
interação foi espaço para a mediação. As postagens que selecionamos demonstram que as estudantes se preocuparam em expressar seu entendimento sobre o assunto, dialogar e provocar a reflexão dos demais. Podemos observar que nos dois exemplos a seguir a mediação por meio da interação ocorreu de forma mais tímida, geralmente entre o autor da postagem e um colega.

Figura 02 - Interação entre estudantes sobre o conceito de cibercultura

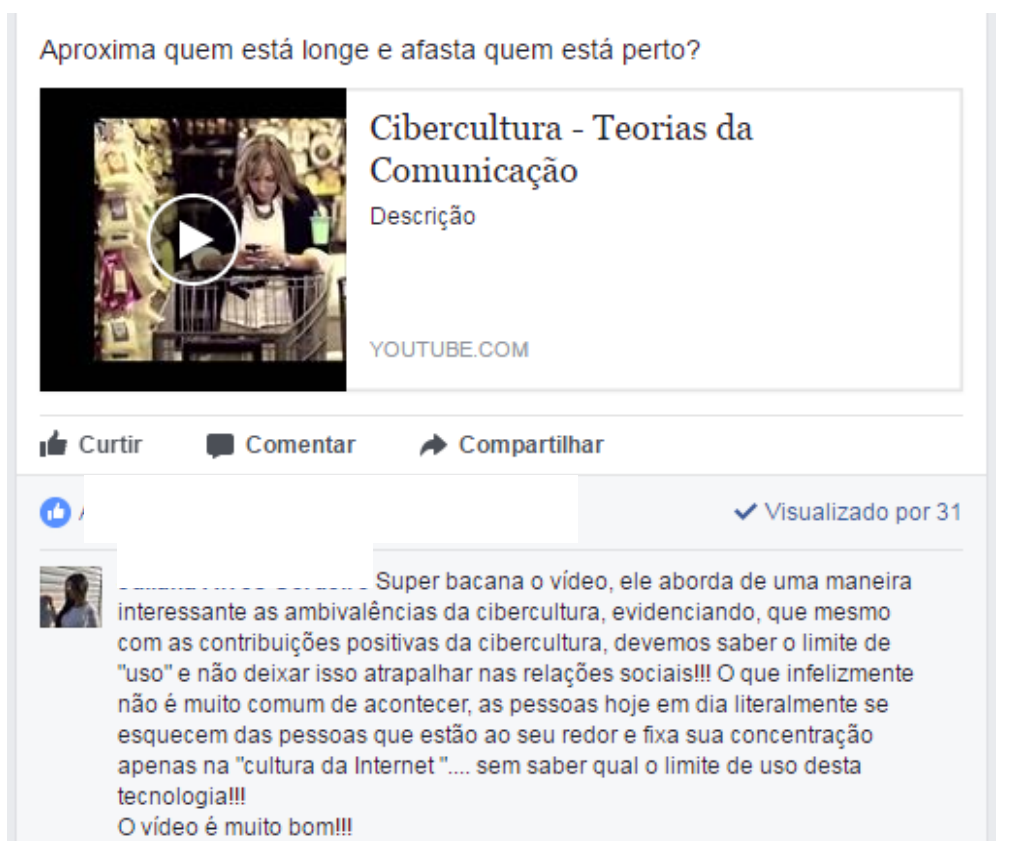

Fonte: Facebook (2018)

$\mathrm{Na}$ imagem a seguir, a aluna 12 postou uma imagem e uma frase. Em seguida, recebeu a contribuição da aluna 15, que compartilhou seu pensamento sobre o assunto e lançou uma reflexão ao final. Na sequência, a aluna 12 interage e expressa sua opinião, nesse caso, concordando com a colega.

Figura 03 - Interação entre duas estudantes na elaboração do conceito 


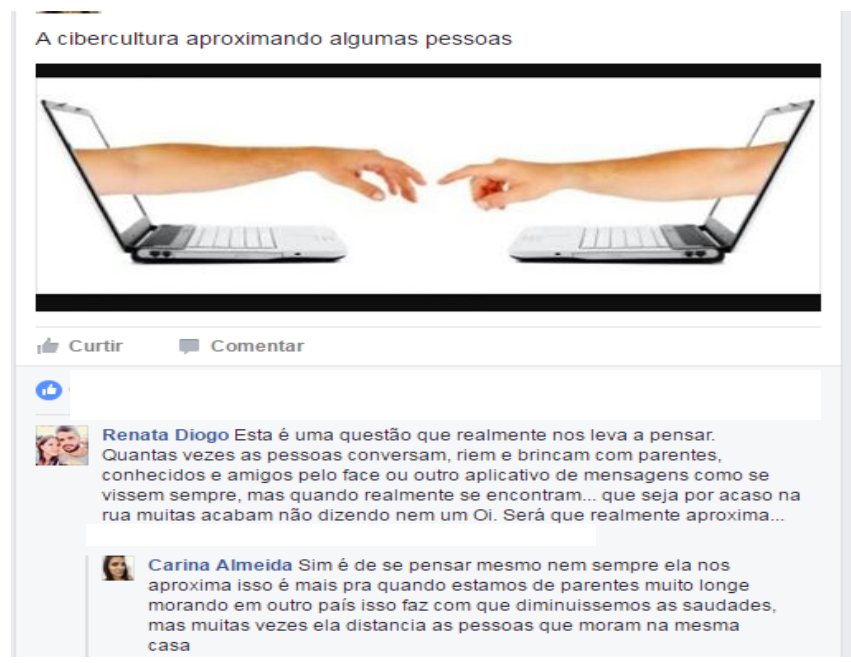

Fonte: Facebook (2018)

Progressivamente, os estudantes foram tomando gosto pela atividade, participando e se expressando mais. Com isso, abriram espaço para a mediação por meio da interação. Salomon (1993) explica que a mediação por meio da interação proporciona a distribuição da cognição quando ocorrer de forma recíproca, ou seja, quando os sujeitos compartilham experiências e conhecimentos com seus pares e também quando têm a oportunidade de confrontar seus conhecimentos e convicções com os de outras pessoas.

Selecionamos duas postagens para ilustrar a evidência da mediação entre pares por meio da interação: a primeira foi uma imagem postada por uma aluna, criticando a sociedade atual. Nesta vemos claramente a intenção das estudantes de provocar reflexões. Apesar de não ocorrer o confronto de ideias, as contribuições favorecem a elaboração de um pensamento crítico sobre o assunto.

Figura 04 - Interação a partir de uma imagem 
SOCIEDADE CAPITALISTA SE APRESENTA COMO SUCIEDADE DO F5PET Á CULD. MPRRIA MAIs A IMAGEM. A APARÊNCIA. A EXIBICÃ̃.

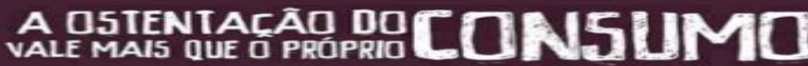
A APARENCIA SE IMPOE A EXISTENCIA. PARECER E MAIS IMPQRTANTE DQ OUE SER" [JACOB GORENDER]

Penso que esse texto se encaixa bem em nossos dias, 0 que "parece ser" é muito mais importante do que de fato é, são coisas camufladas e superficiais, felicidades camufladas e sentimentos de querer ser mais do que os outros são, ou melhor ser mais do que o outro mostra ser, isso é muito comum. Também penso que é uma caracteristica da nossa sociedade capitalista que incentiva o consumismo e dá a impressão de que você só vai ser feliz se comprar aquilo, porém a coisa fica muito pior, porque agora não é só comprar e consumir, agora é MOSTRAR que consome. Não importa o que somos mais, o que importa para alguns é o que mostramos ser.

Alil Andei pesquisando sobre esse assunto(que me chamou muito atenção).

É uma teoria crítica à respeito do capitalismo e das transformações advindas dele na sociedade.

Quanto mais é produzido mais capital gera, a partir disso a sociedade não enxerga mais a imagem passa a consumi-la. O espetáculo se instaura quando a mercadoria passa a ocupar o estilo de vida ideal, a mercadoria deixa de ser produto e passa a ter valor quase divino(adoração), nos alienamos por estarmos diante de relações de dominação ao interagirmos socialmente.

Tudo que vivemos passa a ser meramente uma representação, o espetáculo se dá através da multiplicação imagens, principalmente pelos meios de comunicação em massa.

Nós somos receptores e propagadores do espetáculo, a realidade não existe por verdade surge do espetáculo e por isso é real. A imagem faz com que nossa realidade seja construida socialmente, através do que nos é mostrado nas mídias... Parâmetros da forma como devemos ser, agir, consumir.... Ainda que não tenhamos real capacidade de transformar a sociedade, postamos falsas alegrias, falsas conquistas, buscando nos encaixar na sociedade perfeita que criaram para nós! É fato! Infelizmente eu faço parte deste espetáculo!

Obs: desculpem os erros, escrevi pelo celular!

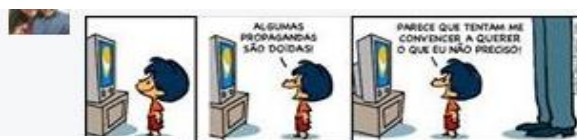

Sim, meninas, é isso mesmo, vivemos para o

1) consumo. Sentimos a necessidade de consumir tudo. No contexto da cibercultura continuamos a consumir.

Fonte: Facebook (2018)

O segundo exemplo foi uma postagem sobre o jogo do Pokémon GO, o qual se constituiu como uma nova prática da cibercultura. Aqui, tivemos a participação de sete estudantes.

Figura 05 - Interação sobre o jogo Pokémon GO 


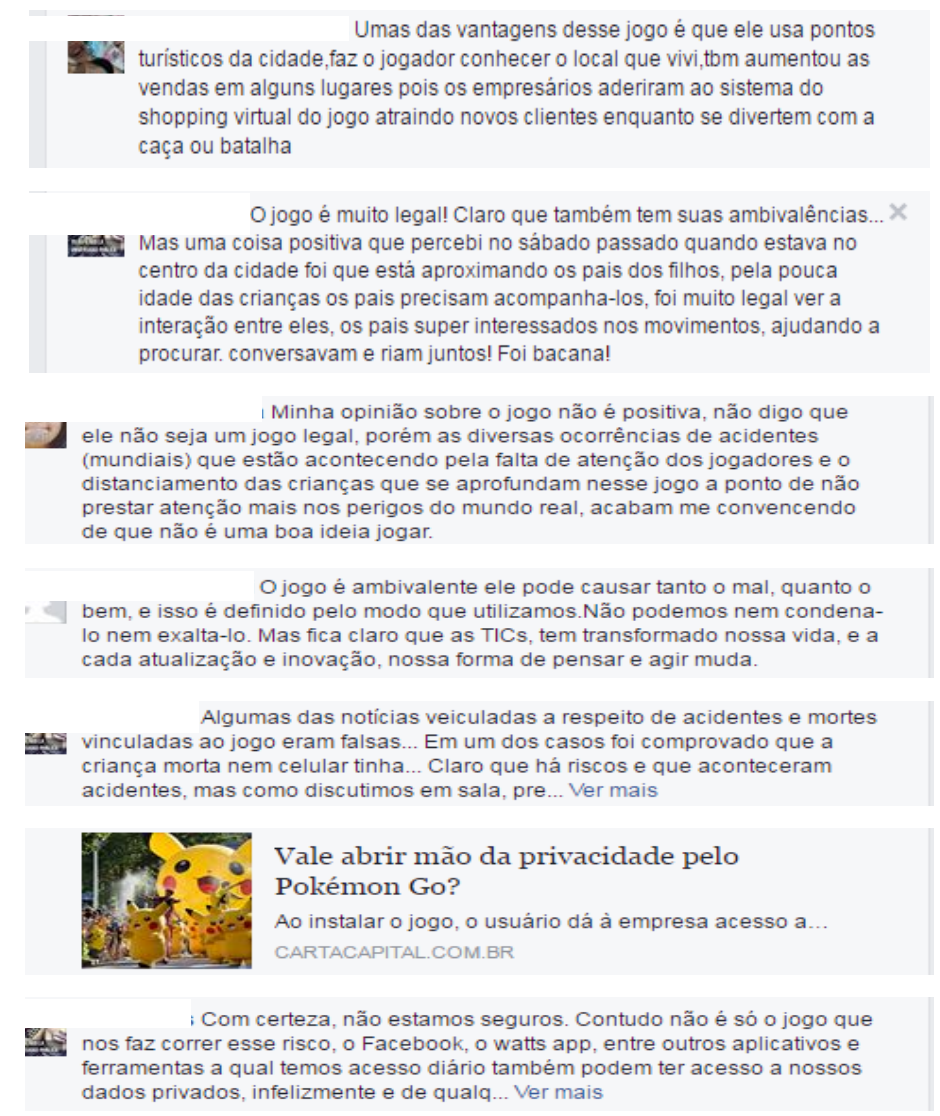

Fonte: Facebook (2018)

Nesse exemplo podemos visualizar, de forma mais clara, o processo de mediação que ocorre por meio da interação, o qual permite o confronto cognitivo e a construção conjunta de significados. A segunda estudante considera uma invenção positiva que conduz as pessoas a conhecerem espaços e aumenta as vendas. Já a quarta estudante vai na direção oposta, e considera o jogo uma ameaça. As demais se posicionam de forma diferente, evidenciando uma compreensão mais crítica e reflexiva, contrapondo-se as colegas. O confronto cognitivo evidenciado nas postagens pode ajudar os estudantes a formarem novos pensamentos. Assim, pela contraposição de ideias, negociação e diálogo, as alunas vão mediando-se entre si e favorecendo o processo de elaboração conceitual.

É importante destacar que, em sala de aula, muitas vezes não ocorrem momentos de confrontos de ideia, de diálogos. Ademais, muitos jovens não se sentem tão à vontade para manifestar o que pensam e, em um espaço como esse, a liberdade de expressão é maior. Assim, pode-se concluir que atividades dessa natureza, realizadas em um ambiente virtual, são favoráveis para mediar as aprendizagens e os processos formativos dos jovens, principalmente quando forem provocativas, desafiadoras, relacionarem o conceito com a realidade do estudante e proporcionarem outras formas de ensinar e aprender conceitos. 
Para Salomon (1992), nossa mente é afetada pelos artefatos, tanto por meio das experiências que decorrem das práticas de uso como pela representação cultural de tais ferramentas na sociedade. $\mathrm{O}$ autor expressa que o potencial dos artefatos "reside na sua capacidade de redefinir e reestruturar fundamentalmente o que fazemos, como fazemos e quando o fazemos [...]” (SALOMON, 1992, p. 149).

O Facebook se tornou um local de encontros em que os jovens se sentiram à vontade para se expressar e participar, evidenciando um processo social de construção de conhecimentos que foi se ampliando pelos próprios usuários. Além disso, os estudantes compartilharam grande quantidade de informação, confrontaram pensamentos, elaboraram sínteses e se ajudaram mutuamente. Sobre os artefatos digitais, Monereo e Pozo (2010, p. 110) expressam que a “[...] pluralidade e o uso integrado de múltiplos códigos tornam possível um conhecimento integrado e multimídia que parece ser o suporte ideal para um pensamento complexo".

Ao final da intervenção, os estudantes foram convidados a responder a um questionário objetivando avaliar a experiência e identificar o que ela representou. Do total de 41 jovens, 36 responderam o questionário e destas foram elencadas categorias de análise. Para os participantes, o Facebook foi avaliado da seguinte forma: ótimo para 55\%, bom, para 30\%, e ruim, para $15 \%$ dos alunos. No tocante ao que essa ferramenta representou para os jovens, identificamos duas categorias: ambiente de aprendizagem, com 86,30\% de frequência, e ferramenta inadequada, com $13,70 \%$.

A categoria ambiente de aprendizagem, com 86,30\%, representa que o Facebook se tornou um espaço de compartilhamento de conceitos, opiniões, informações, discussões significativas e mediação das aprendizagens. Para os jovens, o Facebook foi interessante, enriquecedor, produtivo e positivo enquanto espaço para realizar as atividades e aprender, pois, além de facilitar e auxiliar a aprendizagem, os fez sair da rotina e da zona de conforto, constituindo-se, assim, como uma forma legal, divertida e nova para aprender conceitos.

O estudo realizado por Goulart e Aarreniemi-Jokipelto (2016, p. 586) considera que as mídias sociais necessitam de “[..] aprofundamento teórico-prático e pode, certamente, se tornar um dos canais informacionais úteis para facilitar e motivar os processos de ensino e aprendizagem".

A seguir, alguns excertos exemplificam:

Gostei muito das atividades realizadas no Facebook. Ela nos fez sair da rotina normalmente vivida em sala de aula, saindo de um certo padrão. Foi divertido usar espaço para aprender (Aluna 24). 
Achei muito interessante, sendo uma forma mais lúdica e informal de entender o conteúdo, onde fica menos cansativo e mais atrativo pra nós que amamos as TDIC (Aluna 36).

Foi uma experiência fácil, prática e rápida, pois não ficamos presos apenas a uma ferramenta. Através do Facebook, além de ser uma ferramenta a mais para compartilhamento de ideias, tive contato com outras ideias e isso me ajudava a formar meu pensamento (Aluno 9).

Sobre o que os artefatos digitais podem oferecer, Regis (2008) destaca que a recombinação de diferentes interfaces em um único dispositivo desafia e estimula os processos cognitivos como atenção, percepção e criatividade, além de exigir o aperfeiçoamento das capacidades táteis, visuais e sonoras. Todo esse diferencial permite que seu uso seja favorável enquanto potencializador dos processos mentais. Nesse aspecto, o digital vai se diferenciando dos anteriores, ao oferecer variadas práticas que podem ampliar e oportunizar o desenvolvimento dos processos mentais.

A categoria ferramenta inadequada para aprender evidencia que o uso do Facebook foi complicado, difícil, confuso e causou apreensão e dificuldades. Além disso, foi pouco proveitoso e, por isso, alguns alunos não gostaram de utilizá-la. Abaixo, alguns excertos relacionados a essa categoria:

Um desafio enorme. Geralmente utilizo o Facebook para postagens aleatórias e apresentar ideias em rede social é meio complicado (Aluna 06).

Particularmente eu não gostei muito. Acho que o Facebook é um espaço para descontração e utilizá-lo como atividade é um pouco chato acho que a finalidade dele não é essa e o torna ruim entrar para fazer isso (Aluna 11).

Os dados expressam que esta ferramenta foi avaliada por uma grande maioria $(86,30 \%)$ como positiva para aprender e, por um grupo menor, como ferramenta inapropriada. Assim, é possível perceber que o facebook apresenta limites e possibilidades nas práticas pedagógicas. Este é um dado que precisa ser levado em consideração no momento de propor práticas curriculares com o uso da rede social. Arguedas-Mendez (2016) recomenda o uso do Facebook na universidade para melhorar a aprendizagem colaborativa, mas alerta sobre a necessidade de buscar estratégias para envolver todos os membros para que participem ativamente.

\section{Considerações finais}


Este estudo evidenciou boas práticas com o Facebook porque este serviu como mediador da aprendizagem e colaborou na formação conceitual dos estudantes. Tal mérito não se atribui à ferramenta em si, mas às relações estabelecidas, às atividades desenvolvidas e àquilo que foi capaz de provocar. As atividades e práticas vivenciadas pelos estudantes $\mathrm{e}$ professor neste ambiente favoreceram a identificação das categorias da teoria da cognição distribuída colocadas em prática: interação, parceria intelectual e participação colaborativa. As mediações que ocorreram neste ambiente também proporcionaram diálogo, expressão e ampliação do pensamento, novas percepções sobre o conceito, confronto cognitivo e a construção conjunta de significados.

Concluímos ainda que o Facebook se tornou um local de encontros em que os jovens se sentiram à vontade para se expressar e participar, evidenciando um processo social de construção de conhecimentos ampliado pelos próprios usuários. Além disso, os estudantes compartilharam grande quantidade de informação, confrontaram pensamentos, elaboraram sínteses e se ajudaram mutuamente. O Facebook constitui um espaço rico de aprendizagem e construção colaborativa, pois o princípio básico da aprendizagem de adultos é o autodirecionamento e a autonomia possibilitada pela maturação orgânica, que ao longo da vida vão se aprimorando, à medida que os estudantes vivenciam novas experiências de aprendizagem.

Ressalta-se na intervenção o fato de todas as atividades desenvolvidas estarem à disposição dos estudantes de forma permanente. A ferramenta propicia que cada estudante, ao postar suas impressões, textos e imagens compare com as postagens de colegas e dialoguem entre si. Desta forma, compreende-se o potencial da ferramenta ao permitir que as produções e autorias dos estudantes não sejam "lacradas" e entregues ao professor com a finalidade de obter nota ou conceito, mas que se configura em um espaço de partilha e produção de sentidos.

Na perspectiva vigotskiana, o instrumento é mediador porque conduz a ação humana, provocando mudanças externamente. Com isso, pode-se concluir que o potencial da ferramenta se concretizou, ou seja, oportunizou aquilo que não seria possível vivenciar de outra forma. As múltiplas interfaces e as práticas de uso desse artefato conduziram os jovens ao entendimento desta não só como recurso, mas como mediadora das aprendizagens que amplia o pensamento. Ao tomar como base as ideias de Vigotski, os autores Wertsch e Tulviste (2013, p. 72) expressam que o uso dos instrumentos mediadores “[...] não facilita simplesmente os processos que ocorreriam de outra maneira. Pelo contrário, ao ser incluída 
no processo do comportamento, a ferramenta psicológica altera integralmente o fluxo e a estrutura das funções mentais".

\section{REFERENCIAS}

ARGUEDAS-MENDEZ, S. M. El Facebook como apoyo a la docencia universitaria: experiencia educativa en un curso de cálculo. Educare, v. 20, n. 1, jan./abr. 2016. Disponível em: http://www.revistas.una.ac.cr/index.php/EDUCARE/article/view/7506/7821. Acesso em: 20 out. 2018.

BROWN, A. L. et al. Distributed expertise in the classroom. In: SALOMON, G. Distributed cognitions: psychological and educational considerations. Cambridge: CUP,1993. p. 188-228.

COLL, C.; MAURI, T.; ONRUBIA, J. A incorporação das tecnologias de informação e da comunicação na educação: do projeto técnico-pedagógico às práticas de uso. In: COLL, C.; MONEREO, C. (Org.). Psicologia da Educação virtual: aprender e ensinar com as tecnologias da informação e da comunicação. Porto Alegre: Artmed, 2010. p. 66-93.

COLE, M.; ENGESTRÖM, Y. A cultural-historical approach to distributed cognition. In: SALOMON, G. Distributed cognitions: psychological and educational considerations. Cambridge: CUP, 1993. p. 01-46.

COSTA, S. R. S.; DUQUEVIZ, B. C.; PEDROZA, R. L. S. Tecnologias Digitais como instrumentos mediadores da aprendizagem dos nativos digitais. Psicol. Esc. Educ., Maringá, v. 19, n. 3, p. 603-610, dec. 2015. Disponvível em:

http://www.scielo.br/scielo.php?script=sci_arttext\&pid=S1413-

85572015000300603\&lng=pt\&tlng=pt. Acesso em: 08 ago. 2018. DOI:

https://doi.org/10.1590/2175-3539/2015/0193912

GOULART, E. E.; AARRENIEMI-JOKIPELTO, P. Estudo comparativo sobre o uso de mídia social em escolas. Revista Ibero-Americana de Estudos em Educação., Araraquara, v. 11, n. 2, p. 575-588, abr./jun. 2016. Disponível em:

https://periodicos.fclar.unesp.br/iberoamericana/article/view/8378. Acesso em 19 dez. 2019. DOI: https://doi.org/10.21723/RIAEE.v11.n2.p575

HERRERO, C.; BROWN, M. Distributed cognition in community-based education. Revista de Psicodidáctica, v. 15, n. 2, p. 253-268, 2010. Disponível em:

https://www.ehu.eus/ojs/index.php/psicodidactica/article/view/816. Acesso em: 27 fev. 2020.

ITO, M. Sociocultural contexts of game-based learning. 2009. Disponível em:

http://sites.nationalacademies.org/cs/groups/dbassesite/documents/webpage/dbasse_080072.p df. Acesso em: 05 jun. 2018.

LEMME, B. H. Development in adulthood. Boston: Allyn \& Bacon, 1995.

VVIDIS, I. K. Distributed cognition and educational practice. Journal of Interactive Learning Research, Creta, v. 13, p. 11-29, 2002. 
MANSOUR, O. Group intelligence: a distributed cognition perspective. In:

INTERNATIONAL CONFERENCE ON INTELLIGENT NETWORKING AND

COLLABORATIVE SYSTEMS, 2009, Washington, D.C. Anais [...] Washington, D.C.:

IEEE, 2009. p. 247-250.

MARTINS, S. M. P. C.; FERNANDES, E. M. dos S. Robots como ferramenta pedagógica nos primeiros anos a aprendizagem como participação. Rev. Bras. Educ., Rio de Janeiro, v. 20, n. 61, p. 333-358, abr./jun. 2015. Disponível em:

http://www.scielo.br/scielo.php?script=sci_arttext\&pid=S1413-

24782015000200333\&lng=en\&nrm=iso. Acesso em: 10 jul. 2018. DOI:

https://doi.org/10.1590/S1413-24782015206104

MATTAR, J. Web 2.0 e redes sociais na educação. São Paulo: Artesanato Educacional, 2013.

MORAES, D. A. F. de. Os processos formativos de estudantes universitários paranaenses e suas relações com os artefatos digitais: uma proposta de mediação didática colaborativa baseada na cognição distribuída. Orientador: Claudia Maria de Lima. 2017. 340 f. Tese (Doutorado em Educação) - Universidade Estadual Paulista Júlio de Mesquita Filho, Faculdade de Ciências e Tecnologia, Presidente Prudente, 2017. Disponível em: https://repositorio.unesp.br/handle/11449/151745. Acesso em: 27 fev. 2020.

MORAES, D. A. F. de; LIMA, C. M. de. Os artefatos digitais como ferramentas culturais mediadoras: possibilidades para novos cenários de aprendizagem. Educar em Revista, v. 35, n. 78, p. 243-262, dez. 2019. ISSN 1984-0411. Disponível em:

https://revistas.ufpr.br/educar/article/view/59642. Acesso em: 03. dez. 2019.

PEA, R. D. Practices of distributed intelligence and designs for education. In: SALOMON, G. Distributed cognitions: psychological and educational considerations. Cambridge: CUP, 1993. p. 47-87.

REGIS, F. Tecnologias de comunicação, entretenimento e competências cognitivas na cibercultura. Revista FAMECOS, Porto Alegre, v. 15, n. 37, p. 32-37, dez. 2008. Disponível em: http://revistaseletronicas.pucrs.br/ojs/index.php/revistafamecos/article/view/4797. Acesso em: 20 set. 2018. DOI: http://dx.doi.org/10.15448/1980-3729.2008.37.4797

SALOMON, G.; PERKINS, D.; GLOBERSON, T. Partners in cognition: extending human intelligence with intelligent technologies. Educational Researcher, v. 20, n. 3, p. 2-9, 1991. Disponível em: https://journals.sagepub.com/doi/10.3102/0013189X020003002. Acesso em: 27 fev. 2020. DOI: https://doi.org/10.3102\%2F0013189X020003002

SALOMON, G. Las diversas influencias de la tecnología em el desarrollo de la mente. Journal: Infancia y Aprendizaje, v. 15, n. 58, p. 143-159, jan. 1992. Disponível em: https://www.tandfonline.com/doi/abs/10.1080/02103702.1992.10822337. Acesso em: 27 fev. 2020. DOI: https://doi.org/10.1080/02103702.1992.10822337

SALOMON, G. Distributed cognitions: psychological and educational considerations. Cambridge: CUP, 1993. p. 47-87. 
SCORSOLINI-COMIN, F. Psicologia da educação e as tecnologias digitais de informação e comunicação. Psicol. Esc. Educ., Maringá, v. 18, n. 3, p. 447-455, dec. 2014. Disponível em: http://www.scielo.br/scielo.php?pid=S1413-

$85572014000300447 \&$ script=sci_abstract\&tlng=pt. Acesso em: 20 set. 2018. DOI: https://doi.org/10.1590/2175-3539/2014/0183766

SMITH, M. C.; POURCHOT, T. Adult learning and development: perspective from educational psychology. London: Lawrence Erlbaum Associates, Inc, 1998.

TEZANI, T. C. R. Nativos digitais: considerações sobre os alunos contemporâneos e a possibilidade de se (re)pensar a prática pedagógica. DOXA: Revista Brasileira de Psicologia e Educação, v. 19, n. 2, p. 295-307, jul./dez. 2017. ISSN 2594-8385. Disponível em: https://periodicos.fclar.unesp.br/doxa/article/view/10955. Acesso em: 10 jul. 2018. DOI: https://doi.org/10.30715/rbpe.v19.n2.2017.10955

WERTSCH, J. V.; TULVISTE, P. L. S. Vygotsky e a psicologia evolutiva contemporânea. In: DANIELS, Harry (Org.). Uma introdução a Vygotsky. São Paulo: Edições Loyola, 2013. p. 61-82.

\section{Como referenciar este artigo}

MORAES, D. A. F.; MELLO, D. E. O ensino de conceitos na universidade: o Facebook como instrumento de mediação didática colaborativa. Revista Ibero-Americana de Estudos em Educação, Araraquara, v. 15, n. 2, p. 361-384, abr./jun. 2020. e-ISSN: 1982-5587. DOI: https://doi.org/10.21723/riaee.v15i2.12391

Submetido em: 22/03/2019

Revisões requeridas: 30/06/2019

Aprovado em: 20/11/2019

Publicado em: 20/02/2020 